\section{Supramolekularer Klettverschluss für die Adhäsion unter Wasser}

Kleben feuchter Oberflächen oder gar unter Wasser stellt noch immer eine Herausforderung dar. Koreanische Wissenschaftler stellen in der Zeitschrift Angewandte Chemie nun mit ihrem supramolekularen „Klettverschluss“ ein völlig neues Konzept vor.

$\mathrm{B}_{\text {sucht, natürliche Unterwasser- }}^{\text {isher haben Forscher vor allem ver- }}$ "Klebstoffe" nachzuahmen, etwa die Haftmoleküle von Muscheln. Solche Substanzen kleben zwar gut im Nassen, allerdings lässt sich die Haftung nicht wieder aufheben. Das Team um Kimoon Kim von der Pohang University of Science Kim und seine Kollegen setzen auf sogenannte Gast-Wirt-Wechselwirkungen zwischen wasserlöslichen Wirtsmolekülen mit einer wasserabweisenden „Tasche“ und ionischen Gastmolekülen mit einem wasserabweisenden Baustein, die in Wasser sehr feste nichtkovalente Bindungen miteinander eingehen. Das Vertreiben der Wassermoleküle ist die treibende Kraft für die Entstehung der Bindung.

Die Forscher wählten Cucurbit[7] uril als Wirt und Aminomethyl-Ferrocen als Gast. Cucurbit[n]urile ( $\mathrm{n}=5,6$, 7, 8 oder 10] sind Makrozyklen - groBe ringförmige Moleküle, die sich aus mehreren Glycoluril-Einheiten zusammensetzen und andere Moleküle in ihrem Hohlraum binden können. Der Name leitet sich von Cucurbita ab, dem lateinischen Namen für Kürbisse, deren Gestalt sie ähneln. Ferrocene sind sogenannte Sandwichverbindungen, zwei aromatische Kohlenstoff-Fünfringe bilden die beiden „Brotscheiben“, zwischen denen sich ein Eisenatom als „Belag“ befindet. Das gewählte Ferrocen lagert sich sehr fest und spezifisch in einen „Kürbis“ aus sieben Glycoluril-Einheiten ein.

Die Forscher stellten verschiedene Silikonstreifen her, auf die viele „Kürbisse“ bzw. viele „Sandwiches“ geknüpft wurden. Kommen diese Streifen in Kontakt, binden sie analog zu einem Klett-

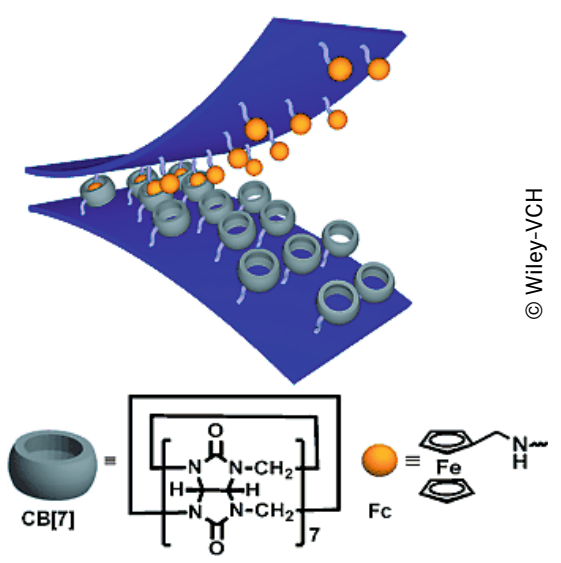

Wie ein Klettverschluss binden die Ferrocene (gelb) in die Cucurbite (grau) und sorgen auch unter Wasser für eine sichere Haftung der Fügeteile (blau).

verschluss sehr fest aneinander. Eine Fläche von $1 \times 1 \mathrm{~cm}$ des supramolekularen Klettbandes hält, aneinander gedrückt, ein Gewicht von 2 kg in Wasser. Nach dem Trocknen in Luft trägt es sogar $4 \mathrm{~kg}$.

Wie ein makroskopischer Klettverschluss kann das molekulare Pendant auch durch kräftiges Abreißen wieder getrennt und mehrere Male wieder verbunden werden. Die Haftung kann aber auch chemisch gelöst werden, nämlich durch Hypochlorit-Lösung, die die Eisenatome oxidiert. Nach einer Reduktion z.B. mit Ascorbinsäure klebt der Klettverschluss wieder.

Da die verwendeten Stoffe bioverträglich sind, wären auch Bio-Anwendungen denkbar - z.B. beim Verschluss von Operationswunden oder bei der „Reparatur" von lebendem Gewebe. Nachgemachte Muschel-Klebstoffe sind hier nicht geeignet, da sie starke Oxidationsmittel für die Aushärtung benötigen.

\section{Entleeren, Fördern, Dosieren}

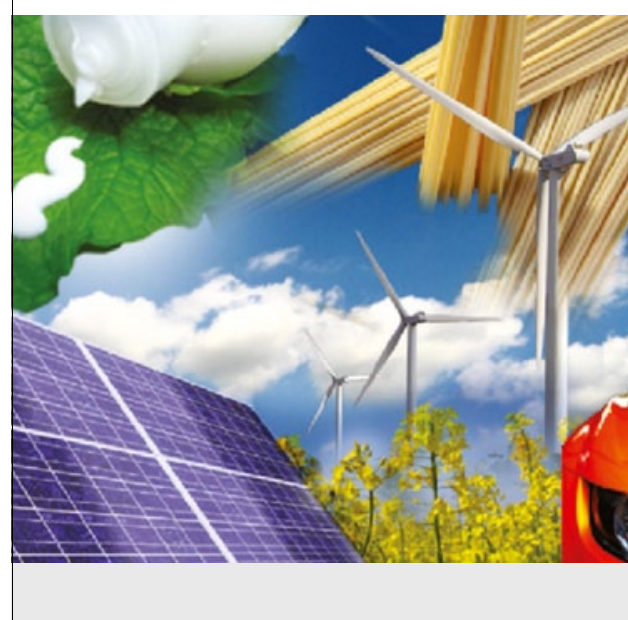

Sie haben die Anwendung, wir die Lösung

NETZSCH zählt zu den richtungsweisenden Problemlösern schwierigster Anwendungsfälle in der Dosiertechnik. Für innovative Dosierlösungen steht Ihnen das breite NETZSCH Produktprogramm zur Auswahl:

- Behälterentleerungen

- Automatisierte Dosierzellen

- $1 \mathrm{~K}$ - und $2 \mathrm{~K}$-Dosiersysteme mit allen Technologievorteilen der NEMO ${ }^{\circledR}$ Exzenterschneckenpumpe

\section{NETZ5대}

\section{NETZSCH Pumpen \& Systeme GmbH}

Dosiertechnik

Tel.: +49 8638 63-2640

Fax: +498638 63-2214

info.nps@netzsch.com

www.netzsch.com

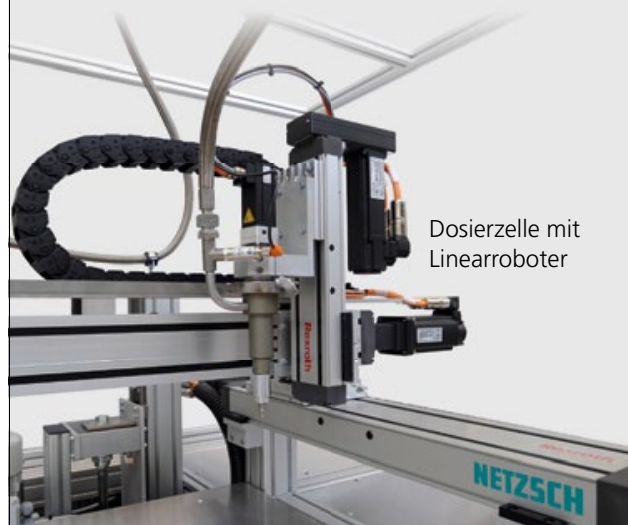

